\title{
The Emerging Web 2.0 Social Media as a Tool to Develop Engaged Audiences for Behaviour Change in Health Promotion: An Overview
}

\author{
Hui-Nee AuYong ${ }^{1, *}$ and Guan-Gim Yeoh $^{2}$ \\ ${ }^{1}$ Faculty of Business and Finance, Universiti Tunku Abdul Rahman, 31900 Kampar, Perak, Malaysia. \\ ${ }^{2}$ Faculty of Information and Communication Technology, Universiti Tunku Abdul Rahman, 31900 \\ Kampar, Perak, Malaysia.
}

\begin{abstract}
Sharing of health information which is related to health becomes easier with the introduction of new technologies such as Web 2.0 social media networks. Social media networks represent a rather innovative way of online information and knowledge repositories. On the other hand, many non-communicable diseases are caused by unhealthy urban lifestyle. Hence, the practice of the healthy lifestyle behaviors should be promoted for sustainability. Besides, in order to cut down the chronic diseases, workplace is one of the key channels for the delivery of interventions among adult populations. Latest development in information and communication technologies (ICT) has given positive influences in health communication. The new technology is believed to be more engaged because it involves visual, audio and animation simultaneously, thus it is more reachable and collaborative. This paper reviews strategies to manage health promotion. Nevertheless, improvement is still needed to achieve successful health promotion. This paper also provides insights of issues and poses future topics of health promotion to consider.
\end{abstract}

\section{Introduction}

With the Economic Transformation Program (ETP), Malaysia aims to transform to a highincome economy. Tee [1] suggested that these changes were coupled with changes to sedentary lifestyle while the diets could also change to high fat and low fiber which contributed to the high-energy content. As a result, the disease pattern is now more inclined to non-communicable diseases. People with metabolic syndrome (MetS) are getting more due to overweight. The practice of unhealthy lifestyle practices may make a person at risk of developing coronary heart disease (CHD) which can be tested such as by a cardiac catheter test [2]. The Malaysian Ministry of Health $(\mathrm{MoH})$ through the Health Education Unit (infosihat) uses ICT dissemination of information in a timely, equitable and innovative manner. Infosihat also utilizes five (5) health promotion strategies [3]. The $\mathrm{MoH}$ has also established Malaysian Health Promotion Board (MySihat) in 2006. One of top five

\footnotetext{
*Corresponding author: auyonghn@utar.edu.my
} 
challenges faced by Malaysian Health Promotion Board is new technologies [4]. Both provision of access to quality healthcare and promotion of healthy lifestyle are implemented for the quality of life improvement [5]. Health information can include following instructions after a doctor's visit, treating a chronic illness, or taking a medication properly [6]. According to [7], tailored messages that succeed in making information relevant appear to stimulate greater cognitive activity. Health promotion is a combination of educational, organizational, economic and environmental supports [8] Studies include [9] and Karan [10] suggest that health campaign are able to change behaviors to a healthy lifestyle. On the other hand, the concept of workplace health promotion lies in preventive strategy.

The process of enabling people to improve their health and increase control over, as defined as health promotion [3]. It was reported that the WHP provided a high return on investment. [11] identified workplace health promotion program return on investment (ROI) at US\$3-\$10 per Dollar invested, which was higher than ROI estimated by the European Agency for Safety and Health at Work [12] which was ROI at 2.5-4.8 Euros per Euro invested. Therefore, these studies show that health promotion is an effective means for improving the health of workers. Wellness at work is important also for influencing positive behavior of the workers. Nevertheless, this concept is still to be understood and implemented by many workplaces. Besides, media campaign with the aim of increasing physical activity has been one of the major health education and promotion activities by the Ministry of Health [13]. The aim of this paper is to review the influence of social media in health promotion.

\section{Review of Past Research}

\subsection{Workplace Health Promotion (WHP)}

Healthcare promotion does not limit to the public healthcare provider only as it gives impacts to the private sectors as well as to the social in general. McLeroy, Bibeau, Steckler and Glanz [14] propose an ecological model for health promotion which focuses attention on both individual and social environmental factors. In monetary terms, [15], found that medical costs fall by about US\$3.27 for every dollar spent on WHP and that absenteeism costs fall by about US\$2.73 for every dollar spent. National Health and Morbidity Survey 2015 [16], indicated that $29.2 \%$ of adults in Malaysia experienced some form of psychological distress. Nevertheless, the study from [17], indicated that there are limited workplace health promotion (WHP) that showed a significant cut down in mean total cholesterol levels and cigarettes smoked. [18] concluded that the wellness programs help in reducing the impact of stress at the workplace, improve overall employee satisfaction, as well as help in reducing absenteeism.

\subsection{Health Communication: Behavioral Models}

In this field, [19] identified that the most frequently quoted theories were the Health Belief Model (HBM), Social Learning Theory, and the Theory of Reasoned Action (TRA). HBM used in health behavior explained health behaviors and actions [20]. On the other hand, Deci and Ryan [21] suggest that Self-Determination Theory (SDT) is a needs-based motivation theory. [22] explains that self-efficacy measures predict what people will do under more specific circumstances in Self-Efficacy Theory (SET).

Social Learning Theory states that to motivate individuals they must be made to evaluate their vulnerability and susceptibility to diseases that have severe outcomes. 
People's beliefs in their collective efficacy to accomplish social change, therefore, play a key role in the policy and public health perspective to health promotion and disease prevention [23]. In this case, people with stronger self efficacy correlate more to healthcare knowledge behaviour. Information, Motivation and Behavioral Skills Model (IMB Model) describes the attitude of prevention, and interprets information that can be translated into action and eventually able to make up their attitudes and behaviors [24].

Besides, there are also emerging health behavioral models reported in the last decade. For instance, [25] reported that the diffusion theory has inspired work on dissemination of public health. [26] anlyzed the individually-centered theories used in the healthcare communication research, which include Goals-Plans-Action Theory, Uncertainty Theories i.e. Uncertainty Reduction Theory and Uncertainty Management Theory, and Action Assembly Theory. Pietromonaco, [27] used the Attachment Theory, while [28] report on other models used in healthcare such as precaution adoption model (PAM), goal setting theories, the elaboration likelihood model, and behavioral self-regulation in a metaanalysis.

\subsection{Potentials of Social Media in Health Communication}

Though social media does not eliminate disparities between groups, these social media tools have lowered barriers in almost all corners of the world. [29] suggest the Internet can be used for persuasive health communication. [30] stresses the importance to ensure a new digital divide are not created. Those who are not actively seeking public health information through the internet have to be identified [31].

Recently, Facebook CEO Mark Zuckerberg launched the company's 10-year technology road map with ways connecting and bringing people together for causes including fighting global disease [32]. The emerging internet has become a main medium to enable health information sharing in various forms. A consumer survey by Ed Bennett Consulting (ebennett.org) quoted by [33] says that $72 \%$ of patients searched for online information before or after a doctor visit. It clearly shows that larger hospitals are early adopters of Social Media. Channel wise, both Facebook (30\%) and Twitter (28\%) are equally popular, with You Tube $(19 \%)$ and Linkedin $(18 \%)$ coming in second. Blogs $(5 \%)$ are a distant third. Consequently, the widely available "mobile" health (m-health) can play an important role in healthcare [34]. According to [35], the definition of Health 2.0 is the use of social software to promote the collaborations among patients, medical professionals and those who are involved in healthcare [35].

Appropriate use of social media can improve user access and satisfaction in obtaining healthcare information. According to [36], World Health Organization has listed that patient use of social media recorded higher satisfaction. [33] also suggest that healthcare organizations to grow business and visibility using the social media. Social media is a leveling of the health playing field through its removal of geographical boundaries and opportunities and connectedness [37]. Social media and Facebook in particular, can benefit more than just a platform for the dissemination of information. Particularly, in a survey conducted by Timian et al. [38], healthcare explored Facebook as an evaluation tool for hospital services through social media.

In contrast, application of social media for public health communication or private health promotion has to be used with care particularly among healthcare professionals. For instance, [39] and [40] warned for the potential harm associated with unsafe social media content, as people seeking health information has to recognize that the authorship is difficult to determine, sources are rarely provided, and users may post their personal opinions in social marketing [41] and cause concerns of inequalities [42], privacy, misinformation and lack of evaluation [43]. For instance, there is a scandal involved 
China's top internet search engine, Baidu, of which the company's search engine provides medical information based on bidding process that caused the death of a university student [44].

With a significant social media presence, health professionals can no longer assume that their authority and social position will afford them greater influence [45]. Hence, one of the health communication research focus suggested by [46] is developing e-health literacy programs to train patients in health information gathering, evaluating, and use. [47] further encourages researchers to work with healthcare professionals and educators for social media educational strategies. This has to be done to overcome challenges encountered by physicians i.e. confidentiality, lack of participation / time / trust, workplace support, and information anarchy [48]. Public health agencies too must develop a strategic communication plan that incorporates best practices [49]. Health promotion must move to high engagement for enhanced communication [50]. They can get people involved in creating environmental and social conditions. In other words, partnerships and participation are viewed as the culmination of social media [51].

\section{Conclusion}

There is a tenacious need to improve the behavioral outcomes of health communication interventions. Public health promotion agency has to embrace use of social media networking which is also important in promoting its trust by the public. Furthermore, promotion of healthy lifestyle should also be extended to the private sector. This is due to the fact that an unhealthy workplace may bring about unsatisfactory / complaint and ultimately turnover of the employees. Hence, Employers should also consider savings against illness related costs as a result of WHP. Other benefits are increased production and improved morale. Intervention programs target the individual, and the work environment also needs consideration. In short, social media has changed communication and furthermore to transforming healthcare. The use of social media in health communication also helps in providing a better understanding to health information.

\section{References}

1. E.S. Tee, Obesity in Asia: prevalence and issues in assessment methodologies, Asia Pacific Journal of Clinical Nutrition, 11, 3 (2002)

2. National Health Service, NHK UK, Coronary Heart Disease - Diagnosis. http://www.nhs.uk/Conditions/Coronary-heart-disease/Pages/Diagnosis.aspx (2016)

3. World Health Organization (WHO), Ottawa Charter for Health Promotion, Geneva (Switzerland) (1986)

4. E. Arps, The Use of Internet and Mobile Phone Based Health Promotion Interventions in Youth Populations, Health Promotion Forum (HPF), Newmarket, Auckland, (2014)

5. Ministry of Health (MOH) Malaysia, Country Health Plan 2011-2015, Putrajaya (Malaysia), (2011)

F.M. Moy, A.A.B.

6. Pfizer (2016). Health Literacy. http://www.pfizer.com/health/literacy

7. M.W. Kreuter and R.J. Wray Tailored and Targeted Health Communication: Strategies for Enhancing Information Relevance, Am. J. Health Beh. (Suppl. 3), (2003)

8. L. Green, and M. Kreuter, Health Promotion Planning: An Educational and Environmental Approach. Mayfield, Mountain View, CA, (1991)

9. L.B. Snyder, Health Communication Campaigns and Their Impact on Behavior, J. Nutr. Educ. Behav., 39, (2007) 
10. K. Karan, Impact of Health Communication Campaigns on Health Behaviors in Singapore, Soc. Marketing Q., 14(3), (2008)

11. Goetzel RZ, Ozminkowski RJ. The health and cost benefits of WHP programs. Annu. Rev. Public Health, Cross Ref. Medline, 29(1), (2008)

12. European Agency for Safety and Health at Work (EU-OSHA), Workplace health promotion improves productivity and wellbeing, Bilbao (Spain), (2010)

13. G. Rampal, L. Rampal and S.H. Lee, Health promotion in Malaysia. In: Health Promotion Theory and Practices. CUHK, Hong Kong, China, (2012)

14. K.R. McLeroy, D. Bibeau, A. Steckler \& K. Glanz, An Ecological Perspective on Health Promotion Programs. Health Educ Behav. 15, 4 (1988)

15. K. Baicker, D. Cutler, and Z.R. Song, Workplace Wellness Programs Can Generate Savings. Health Affairs. 29, 2, (2010)

16. Institute for Public Health (IPH), The Third National Health and Morbidity Survey 2015. Kuala Lumpur, Malaysia: Ministry of Health (MOH), (2015)

17. F.M. Moy, A.A.B. Sallam, \& M.L. Wong, The results of a worksite health promotion Program in KL, Malaysia. Health Promo. Int. 21,4, (2006)

18. D.N.M.A. Abdullah, A. Ali, and Y.L. Oon, A Study on the Relationship bet. Coporate Wellness Programs and Employees' Stress, Job Satisfaction \& Absenteeism, (2008)

19. K. Glanz, F.M. Lewis, and B.K. Rimer, Health Behavior And Health education: Theory, research, and practice, San Francisco, CA: Jossey-Bass, (1990)

20. M.H. Becker, R.H. Drachman, and J.P. Kirscht, A new approach to explaining sickrole behavior in low-income populations. Am J. Public Health. 64, (1974)

21. E. L. Deci, and R. M. Ryan, Intrinsic Motivation and Self-Determination in Human Behavior. New York: Plenum Press, (1985)

22. A. Bandura, Self-Efficacy: The exercise of control. New York: Freeman, (1997)

23. A. Bandura, Health promotion from the perspective of social cognitive theory. Psychol. and Health, 13, (1998)

24. J.D. Fisher \& W.A. Fisher Changing AIDS risk behavior. Psychological Bulletin, 111, $3(1992)$

25. L.W. Green, J.M. Ottoson, C. Garcia, and R.A. Hiatt, Diffusion Theory and Knowledge Dissemination, Utilization, and Integration in Public Health, Annu. Rev. Public Health, 30, (2009)

26. C.L. Bylund, E.B. Peterson, K.A. Cameron, A practitioner's guide to interpersonal communication theory: An overview and exploration of selected theories, Patient Educ. Couns., 87, 3 (2012)

27. P.R. Pietromonaco, B.Uchino, and C.D. Schetter, Close Relationship Processes and Health: Implications of Attachment Theory for Health and Disease, Health Psychol., 32(5), (2013)

28. E. DeLeon, L.W. Fuentes and J.E. Cohen, Characterizing Periodic Messaging Interventions Across Health Behaviors and Media: Systematic Review, J. Med. Internet Res., 16, 3, (2014)

29. M.M. Cassell, C. Jackson, B. Cheuvront, Health Communication on the Internet: An Effective Channel for Health Behavior Change? J. Health Comm., 3 (1998)

30. E. Arps, The Use of Internet and Mobile Phone Based Health Promotion Interventions in Youth Populations, Health Promotion Forum (HPF), Newmarket, Auckland, (2014)

31. O. Washington, Using Social Media Platforms to Amplify Public Health Messages, Georgetown University (2010)

32. Facebook, Technology to Connect the World: F8 Day One Roundup, $12^{\text {th }}$ April 2016, http://newsroom.fb.com/news/2016/04/f8-2016-day-1/ (2016)

33. Wipro (www.wipro.com), Impact of Social Media in Healthcare, (2010) 
34. J.G. Kahn, J.S. Yang, and J.S. Kahn, 'Mobile' Health Needs and Opportunities in Developing Countries, Health Aff., 29, 2, (2010)

35. J. Sarasohn-Kahn, The Wisdom of Patients: Healthcare Meets Online Social Media, California Healthcare Foundation, (2008)

36. C. Hawn, Take two aspirin and tweet me in the morning: How Twitter, Facebook, and other social media are reshaping healthcare, Health Aff., 28, 2 (2009)

37. R. Gorham, L. Carter, B. Nowrouzi, N. McLean, \& M. Guimond, Social Media \& Health Edu: What the Early Literature Says, Intl. J. E-Learning \& Edu, 26, 2 (2012)

38. A. Timian, S. Rupcic, S. Kachnowski \& P. Luisi, Do patients "like" good care? Measuring hospital quality via Facebook, Am J Med Qual., 28, 5 (2013).

39. G. Eysenbach, and C. Köhler, Does the Internet harm health? Database of adverse events related to the internet has been set up, British Med. J., 324, (2002)

40. A.Y.S. Lau, E. Gabarron, L. Fernandez-Luque and M. Armayones, Social media in health, Health Info Mgmt J, 41, 2 (2012)

41. K. Vance, W. Howe, R.P. Dellavalle, Social Internet Sites as a Source of Public Health Information, Dermatol Clin., 27, 2 (2009)

42. F. Khatun, A.E. Heywood, P.K. Ray, S.M.A. Hanifi, A. Bhuiya, S.T. Liaw, Determinants of readiness to adopt mHealth in a rural community of Bangladesh, Int. J. Med. Inform., 84, (2015)

43. A.F. McGloin and S. Eslami, Digital and social media opportunities for dietary behavior change, Proc. of the Nutr. Soc., 74, (2015)

44. S. Jiang, Student death triggers probe of China's Baidu, CNN Money, http://money.cnn.com/2016/05/03/technology/baidu-china-student-death/ (2016)

45. G. Bodie, M.J. Dutta, Understanding Health Literacy for Strategic Health Marketing: E-Health Literacy, Health Disparities, and the Digital Divide. Health Mkt Q., 25, 1, (2008)

46. M.J. Dutta, Health Communication: Trends and Future Directions, in J.C. Parker and E. Thorson (Eds.) Health Commun. in the New Media Landscape, 59-92, (Springer Publishing Co., New York, 2009)

47. D. Currie, Public health leaders using social media to convey emergencies: New tools a boon, Nations Health, 39, 6, (2009)

48. S. Panahi, J. Watson and H. Partridge, Social media and physicians: Exploring the benefits and challenges, Health Inform. J., 22, 2, (2016)

49. R. Thackeray, B.L. Neiger, A.K Smith and S.B. Van Wagenen, Adoption and use of social media among public health departments, BMC Public Health, 12, 1, (2012)

50. B.L. Neiger, R. Thackeray, S.A. Van Wagenen, C.L. Hanson, J.H. West, M.D. Barnes, M.C. Fagen, Use of Social Media in Health Promotion: Purposes, Key Performance Indicators, and Evaluation Metrics, Health Promo. Prac., 13, 2, (2012)

51. B.L. Neiger, R, Thackeray, S.H. Burton, C.G. Giraud-Carrier, M.C. Fagen, Health Promo. Prac., 14, 2, (2013) 